\title{
A CASE OF ALOPECIA AREATA, ASSOCIATED WITH A FOCUS OF DENTAL ORIGIN
}

\author{
Miglena Balcheva, Metodi Abadjiev \\ Prosthodontic Department, Faculty of Dental Medicine, \\ Medical University - Varna
}

\section{INTRODUCTION:}

The focus is a clinically latent local inflammation with a few symptoms that can cause disturbance in the general reactivity of the body. Most of the focuses in children are of tonsillar origin, but in the adults the dental fields of disturbance prevail. They result in a variety of diseases and disorders - renal, joint, heart, dermal, etc. And the proper treatment requires a team collaboration of different well-grounded dental and medical specialists, respectively.

\section{PURPOSE:}

Our purpose is to show the connection between the dental focus and the main illness and to suggest a possible way to manage this problem with a fixed retainer.

\section{METHODS AND MATERIALS:}

This survey presents a case of a 4.5-year old boy, who came to us 5 months after a trauma. He had no pain, only a swelling in 51, 61region. Three months later his mother noticed an empty spot in his hair. They visited a dermatologist- the diagnosis was Alopecia areata and the recommendation - to see the dentist and cure the teeth.

The conventional focal diagnostic tests are not applicable at that age, so we can rely only on the medical history and current status in order to formulate a correct diagnosis and suitable treatment.

The clinical examination revealed an unsuccessful root canal treatment of 61 - the tooth was open, there was a fistula. The Xray also showed a picture of periodontitis. A specialist examined him and confirmed that his tonsils are healthy. The child had an allergic background as well - he developed an urticarial rash as a reaction to Paracetamol 2 years earlier and allergic rhinitis later.

The tooth was extracted. Then a retainer with acrylic tooth was fixed to the adjacent teeth. This retainer is replaced every six months in order not to stop the growth of the bone.

\section{RESULT:}

Two months after the manipulations the empty spots in the hair are almost disappeared. The intraoral status is perfect. The bone growth is in normal range. Now, seven months from the beginning of the treatment, the dermal problems are solved and the second retainer is placed in mouth.

\section{DISCUSSION:}

A lot of medical problems are with uncertain origin. Sometimes the ethiology is only hypothetical, and in other cases it is complex and multi-causal. This involves an interdisciplinary approach in planning and treating with the participation of dentists, oto-rhyno-laryngologists, allergists, dermatologists, endocrinologists, infectionists, cardiologists. The treatment should also be ethiological first and then symptomatic. That's why general dental practitioners and dental specialists, or oto-rhynolaryngologists respectively, cure the supposed focus initially, and then the other medical specialists treat the other diseases and disorders. The patients' collaboration is very important as well to observe strictly the prescribed therapy and to avoid of paramedical measures.

\section{CONCLUSION:}

Focal infection is wide-spread problem and this technique is an easy way to manage it and its consequences. It is a fine example of quickly and well-done complex work.

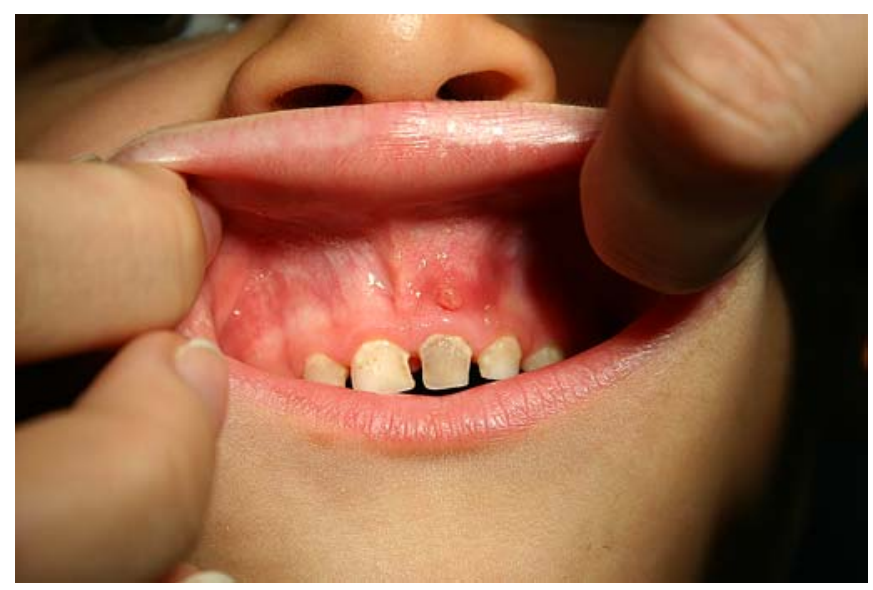

Fig. 1. Intraoral view before treatment. 


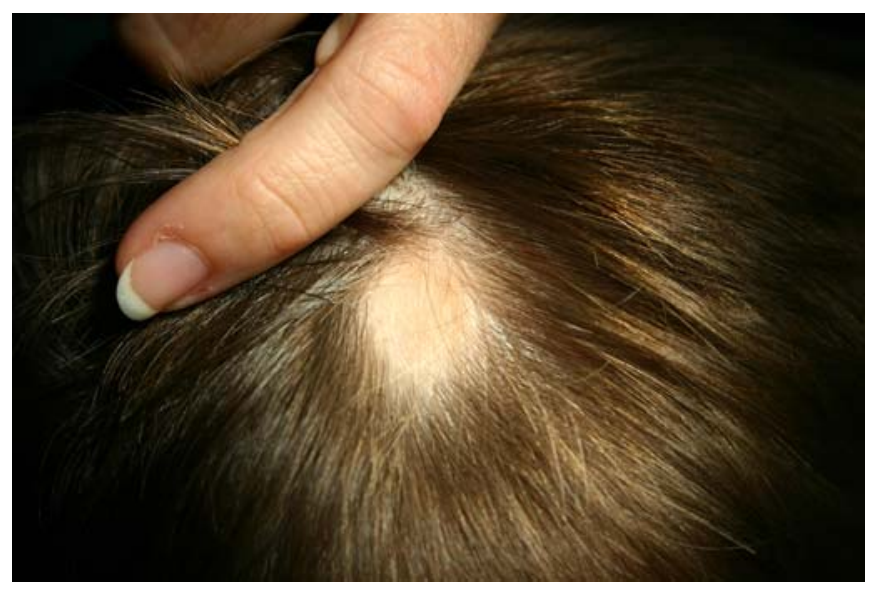

Fig. 2. Alopecia areata before treatment.

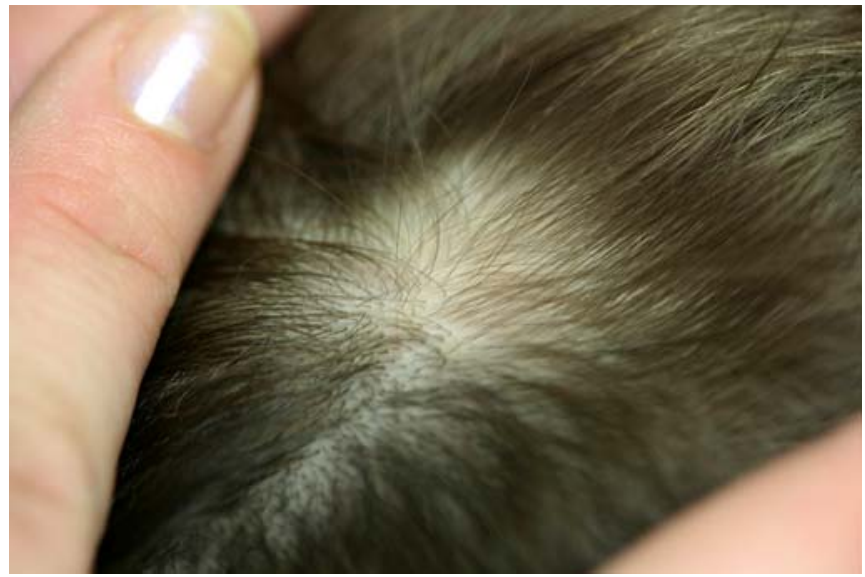

Fig. 4. Alopecia areata -2 months after the extraction - the initial spot.

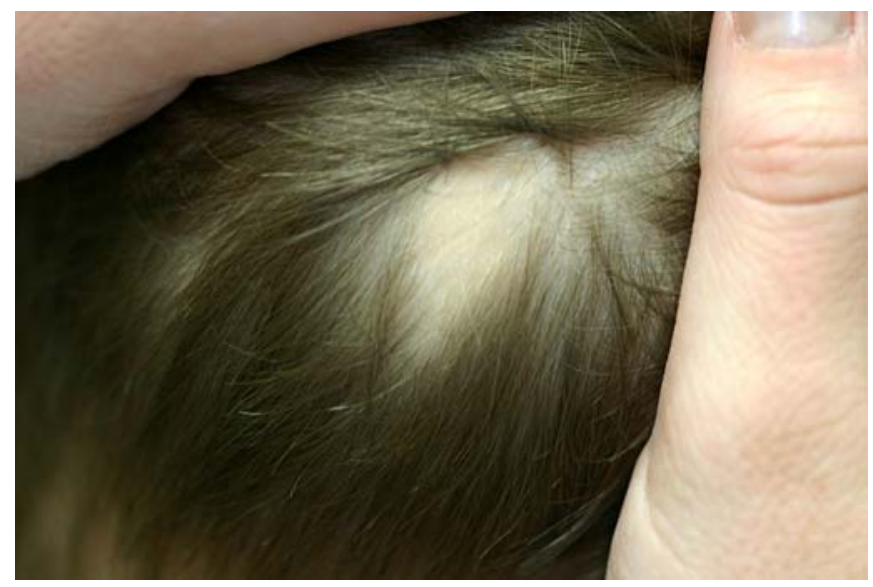

Fig. 3. Alopecia areata -1 months after the extraction

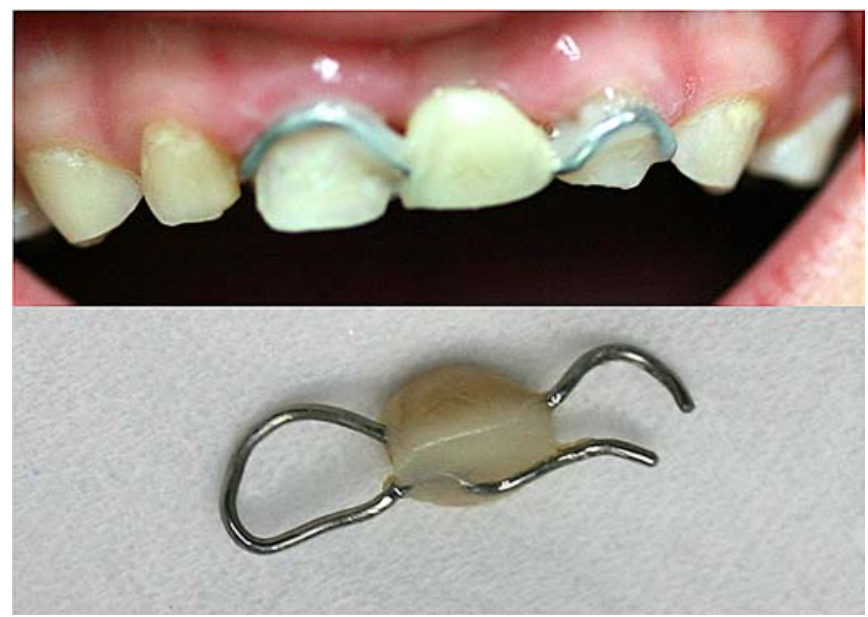

Fig. 5. The retainer and the retainer fixed to the adjacent teeth

\section{REFERENCES:}

1. Goh C., Finkel M., Christos P. J., Sinha A. A. J Eur Profile of 513 patients with alopecia areata: associations of disease subtypes with atopy, autoimmune disease and positive family history. Acad Dermatol Venereol. 2006 Oct;20(9):1055-60

2. Kisselova-Yaneva A. Dental Allergology and Focal Diagnostic.

\section{"Gutenberg" 2001}

3. Zlatkov N. B. Dermatology and Sexually Transmitted Diseases. "Arso" 1999

Address for correspondence:

Miglena Balcheva

Prosthodontic Department, Faculty of Dental Medicine,

Medical University - Varna

63, G.S.Rakovski Str., 9000 Varna, Bulgaria

E-mail: dr_balcheva@abv.bg 